\title{
UMA FILOSOFIA POLÍTICA PARA A CRISE DO CAPITAL
}

\author{
Aluisio Pampolha Bevilaqua ${ }^{1}$
}

\section{Resumo:}

O objetivo deste artigo é apresentar evidências e sustentar a hipótese de que a crise do capital ruiu o substrato material do racionalismo vulgar, deflagrou uma crise de paradigmas na ciência moderna, conduzindo ao retorno do irracionalismo no discurso pós-moderno, e ao debate do fundamento filosófico da teoria marxista - a dialética materialista. Este novo período da sociedade e do pensamento humano, caracterizado de transição, exige dos sujeitos cognoscentes compreender as novas formas de desenvolvimento das relações sociais, em que ciência e educação, mais que paradigmas normativos, são valores basais da humanidade, logo, uma nova rasion d'être e finalidade para a crise do capital em termos transcendentais histórico-filosóficos.

Palavras-chaves: Crise, Capital, Filosofia, Marxismo.

\begin{abstract}
:
This paper aims to present evidence and support the hypothesis that the crisis of capital has made the material substratum of vulgar rationalism collapse, has sparked the crisis of paradigms in modern science, leading to the return of irrationalism in the postmodern discourse and to the debate on the philosophical foundations of Marxism - dialectical materialism. This new period of society and of human thought, characterized by a transition, requires that conscious subjects understand the development of new forms of social relations, in which science and education, more than normative paradigms, are base values of humanity, hence, a new rasion d'être and purpose for the crisis of capital in transcendent historical and phylosophical terms.
\end{abstract}

Keywords: Crisis, Capital, Philosophy, Marxism

\section{Introdução}

A crise do capital que voltou a se manifestar de forma aguda na economia dos Estados Unidos e Europa na primeira e segunda década (2008-2012) do século XXI configura-se, cada vez mais, como expressão dramática dos estertores de um sistema social - o capitalismo -, que luta por não perecer frente suas contradições intrínsecas (cf. MARX, 1973; LENINE, 1985). Enquanto tal, a crise sugere ao pensamento

\footnotetext{
${ }^{1}$ Cientista Social, Mestre em Educação Brasileira e Doutorando em Educação pela UFC, Bolsista do CNPq e Pesquisador do Labor e do CEPPES. Autor do livro: A Crise do Capital em Marx e as Implicações nos Paradigmas da Educação.
} 
dominante, por um lado, imagens e predições cataclísmicas e irracionais em relação à sua natureza e finalidade histórica, conduzindo os sujeitos sociais à ações desesperadas e para uma conjuntura de extrema incerteza em relação aos paradigmas dominantes que fundam as estruturas de relações sociais vigentes - do maior ao menor grau de desenvolvimento socioeconômico, científico-técnico e político-cultural (cf. MARX, 1977); por outro lado, revela também uma crise de paradigmas na ciência decorrente da profunda fissura do substrato material que sustenta o racionalismo vulgar, dominante da concepção geral da sociedade e da própria ciência moderna, exigindo o repensar filosófico com mais e não menos ciência na definição conceitual deste fenômeno social: seja como objeto para si inédito no movimento histórico do modo de produção do capital; seja como objeto em si universal e comum a todos os processos de transições de uma etapa à outra na história dialética das sociedades humanas (cf. LENINE, 1986).

O objetivo deste artigo é apresentar evidências e sustentar a hipótese de que a crise do capital, ao ruir o substrato material em que se fundamenta o racionalismo vulgar, deflagrou uma crise de paradigmas na ciência moderna, conduzindo ao retorno do irracionalismo presente no discurso pós-moderno, metafísico e, por outro lado, ao fundamento filosófico da teoria marxista - a dialética materialista (cf. GRAMSCI, 1971). Ele se constitui de quatro partes: 1) Introdução, que apresenta a questão temática; 2) O desenvolvimento, que descreve as evidências e analisa as relações entre dados empíricos e categorias conceituais, sustentando a hipótese problemática e possíveis soluções; 3) a conclusão, que argumenta a validade da hipótese a priori ou declina a mesma sugerindo nova hipótese e, 4) as referências bibliográficas. O método aplicado é o método do materialismo dialético e histórico, fundado em Marx, Engels e Lenine.

\section{A Crise do Capital e a Crise de Paradigmas da Ciência}

A crise na economia mundial se apresentou nos EUA e Europa empiricamente nos seguintes fatos: a) a bancarrota da Nasdaq em março de 2000 (cf. SHILLER, 2008);

b) os custos de guerra de US\$ 3 trilhões dólares no déficit dos EUA (cf. BILMES; STIGLITZ, 2008); c) a crise nos títulos de hipotecas subprime nas mãos dos Hedge Funds em julho de 2007 (cf. SHILLER, 2008); d) a bancarrota das companhias Fannie Mae e Freddie Mac quebra a Lehman Brothers em setembro de 2008); e) a bancarrota das três gigantes automotrizes estadunidenses: Ford, Crysler e General Motors (cf. KRUGMAN, 2009), e f) finalmente, na Europa, a crise se apresentou mais sentidamente

\begin{tabular}{|l|l|l|l|l|}
\hline Revista Dialectus & Ano 1 & n. 2 & Janeiro-Junho 2013 & p. 50-59 \\
\hline
\end{tabular}


na forma de dívida pública: Irlanda, Grécia, Portugal, Itália e Espanha. Em síntese: o PIB mundial caiu de $3 \%$ em 2008, para $-0,6 \%$ em 2009; queda de $-3,6 \%$. Nas economias avançadas (G-7) o PIB passou de 0,2\% em 2008, para -3,4\% em 2009; queda de $-3,6 \%$ (EUA de 0,4\% para $-2,4 \%$, União Europeia de $0,9 \%$ para $-4,1 \%$, com a Zona do Euro de $5,5 \%$ para $-6,6 \%$ e o Japão de $1,2 \%$ para $-5,2 \%$ ) (cf. IMF, 2010).

A crise na política suscitou imagens metafóricas que vão da turbulência ao tsunami. O vice-presidente do Banco da Inglaterra, Charles Bean, explicou que "é uma crise que acontece uma vez na vida, e possivelmente a maior crise financeira deste tipo na história da humanidade”. O presidente francês, Nicolas Sarkozy, afirmou que "A crise é mundial, estrutural e não é um parêntese que será fechado em breve”. Alan Greenspan a descreveu como "um tsunami de crédito que acontece uma vez por século.". O secretário-geral da ONU, Ban Ki-moon, pediu medidas “drásticas” (...) contra a crise financeira global que "pode ser uma turbulência à qual muitas das pessoas dos países pobres não poderão sobreviver... ameaça todos os progressos que fizemos para combater a pobreza e a doença, nossos esforços contra as mudanças climáticas..." (BEVILAQUA, 2011).

Diante destas evidências empíricas, o problema teórico-filosófico tornou-se inescamoteável, sobretudo, na ciência econômica. Nesta, a questão se apresenta inteiramente ao se indagar: por que o marginalismo - monetário e historicista - não foi capaz de predizer e evitar as crises? Naturalmente, não é razoável uma resposta ad hoc, como a proposição do ex-presidente do FED (Federal Reserve), Alan Greenspan, que passou à história no contradictio in adjecto da "Exuberância Irracional dos Mercados". Esta formulação tornou-se debate acadêmico com a publicação do livro "Irrational Exuberance”, do Professor Robert J. Shiller, que explicou o problema nos seguintes termos:

\footnotetext{
Por que as pessoas ainda se referem aos anos de exuberância irracional? (...) Muitas pessoas foram perceptivas que no contínuo impulso do mercado de ações, como a grande onda dos anos 90, havia algo palpavelmente irracional no ar, ainda que fosse de natureza sutil a irracionalidade. (...) A exuberância irracional não é aquela loucura. Por sua vez - pensar como uma mania ou pensar como uma orgia - em termos populares - parece demasiado forte para descrever o que atravessávamos nos anos de 1990. Foi mais como uma espécie de mau juízo que nos lembramos ter feito em algum momento de nossas vidas quando o nosso entusiasmo adquiriu o melhor de nós. A exuberância irracional parece um termo muito descritivo para o que acontece em mercados quando eles saem da linha (SHILLER, 2005).
}

Mas esta explicação de Shiller também não convence, pois fundamenta a proposição a partir do "lapso de memória" ou "inocência", o que não é aceitável para

\begin{tabular}{|l|l|l|l|l|}
\hline Revista Dialectus & Ano 1 & n. 2 & Janeiro-Junho 2013 & p. 50-59 \\
\hline
\end{tabular}


um sistema teórico que tem por subteorias a tese da "expectativa racional" de Robert Lucas e a tese da "expectativa adaptativa" de Milton Friedman e Edmund Phelps. Estas formulações fizeram da teoria da "Curva de Phillips"2 um instrumento fundamental das metas de inflação macroeconômicas utilizadas pelas instituições governamentais e privadas (cf. MANKIW, 2006, p. 3-5) ${ }^{3}$. Portanto, a questão permanece sem resposta, na verdade, a tese da "Exuberância Irracional" é mais um modo de dizer "risco moral", "efeito pangloss"4 (KRUGMAN, 2009; SHILLER, 2003), isto é, atribuir a explicação da crise a um fator subjetivo (psicológico) e irracional (metafísico), que nem de perto indica objetivamente a natureza e implicações da mesma para a sociedade. E este fato conduz à problemática teórica do presente artigo: as crises gerais, como realidades imanentes à produção social do capital, são ou não crises típicas do capitalismo, segundo os paradigmas da macroeconomia e sua vã filosofia?

As evidências apresentadas neste trabalho sustentam que as crises atuais não correspondem aos modelos teóricos da macroeconomia, limitados ao racionalismo positivista sob fundamento metafísico. Por um lado, porque considerando o dilema ético-existencial humano denunciado por Marx, em relação à tese do equilíbrio natural dos mercados - "pela mão invisível" - pressupõe a crise como mecanismo darwinistamalthusiano implícito à economia política clássica, que reverbera a humanidade pela autodestruição seletiva: dos mais fracos, dos pobres; da classe que "produz seu próprio produto como capital” (MARX, 1985, Liv I, Vol II, p. 209-210). Por outro lado, porque o neokeynesianismo e o neoliberalismo, como teorias, pressupõem a incorporação, em parte, da crítica do socialismo utópico, do anarquismo e do marxismo, como já se observa em Mill (1996, Vol I, p. 183-189, passim e Vol II, p. 405-408, passim), Keynes (1985, p. 241) e até mesmo Friedman (1982, p. 173); e, finalmente, porque a própria abordagem marxista contemporânea sustenta que a "tese da pauperização (...) hoje é citada $a d$ nauseam" (MÈSZÁROS, 2002, p. 521).

Deste modo, a hipótese deste trabalho - de que as crises atuais não

\footnotetext{
${ }^{2} \mathrm{O}$ conceito teórico da Curva de Phillips, compreende a relação inversa entre salário e emprego, adaptada para fixar metas de inflação macroeconômicas. Seu nome foi atribuído pelos economistas Paul Samuelson e Robert Solow em reconhecimento ao economista Alban William Phillips que a formulou pela primeira vez.

${ }^{3}$ Palestra proferida na Universidade de Harvard, Cambridge, MA, em maio de 2006.

${ }^{4}$ Dr. Pangloss, personagem criado por Voltaire no romance Cândido, sustenta a filosofia que o mundo é perfeito e todos os fatos e coisas são explicáveis pela lógica causal - a lógica de Leibniz (que é representado no romance por Pangloss). Voltaire critica Leibniz apoiado em Rousseau e em seu próprio pragma, como se observa na seguinte resposta de Cândido após toda a explicação causal da história por Pangloss: "tudo isto está muito bem dito, mas devemos cultivar nosso jardim" (VOLTAIRE, 1759, p. 187).
} 
correspondem aos modelos teóricos da macroeconomia - constitui proposição plausível, pois se fundamenta no fato desta disciplina não ser consequente para com seu objeto, logo, permite sugerir que as crises atuais são momentos de negação objetiva dos paradigmas teóricos da macroeconomia. As evidências que sustentam a problemática teorética são deduzidas, com suficiente clareza, da comunicação do economista Joseph Stiglitz, ao receber o Nobel em 2001:

\begin{abstract}
Mas qualquer disciplina tem uma vida própria, um paradigma dominante, com os pressupostos e convenções. (...) Por mais de uma centena de anos, a modelagem formal na economia tem-se centrado nos modelos como se a informação fosse perfeita. (...) seguindo a máxima de Marshall "Natura non Facit saltum" (...) Um dos principais resultados de nossa pesquisa foi mostrar que isto não é verdade (...) O paradigma dominante do século XX, o modelo neoclássico, ignorou as advertências do século XIX e mestres anteriores, (...) talvez porque isso teria levado à conclusões desconfortáveis sobre a eficiência dos mercados (STIGLITZ, 2001, p. 475).
\end{abstract}

Elas também se apoiam no livro do Nobel em Economia de 2008, Paul Krugman, De Regresso à Economia da Depressão reeditado em 2009, quando afirma:

Em 2003, Robert Lucas, um professor da Universidade de Chicago galardoado com o Prêmio Nobel da Economia em 1995 (...). Depois de explicar que a macroeconomia surgiu como resposta à Grande Depressão, declarou que (...): 'O problema fulcral de prevenção da depressão' [...] 'foi resolvido em todos os seus aspectos práticos'. (...) Um ano depois, Ben Bernanke, um antigo professor de Princenton (...) da Reserva Federal - e que em breve seria nomeado presidente deste organismo - fez um discurso notoriamente otimista intitulado 'A Grande Moderação', no qual, à semelhança de Lucas, defendia que a política macroeconômica moderna resolvera o problema do ciclo econômico (...) Quando, escassos anos decorridos, com a maior parte do mundo mergulhado numa crise econômica e financeira que em tudo recorda a da década de 1930, encaramos em retrospectivas estas declarações otimistas, parecem-nos duma presunção que quase nos custa acreditar (KRUGMAN; 2009, p. 15-16).

Portanto, parece bastante razoável sustentar esta linha hipotética problemática bem como sustentar, ainda, que a maior parte da literatura especializada atual pretende explicar a natureza e implicações desta sobre a sociedade e indivíduos sociais, a partir de trabalhos fundamentados nos paradigmas dominantes da ciência econômica, que relacionados à teoria da estrutura das revoluções científicas em Thomas Kuhn (1971, p. 114-115), sugerem a "anomalia" da ciência e configuram um quadro de "crise de paradigma"; justificando teoricamente porque as crises econômicas, de per si, objetivamente, negam tanto os paradigmas oficiais, como as análises assentadas nos mesmos, e assim, sinalizam uma profunda contradição entre a teoria econômica e a realidade concreta.

Mas, a crise do capital não é apenas negação objetiva do paradigma teórico neoliberal, ela também fez reemergir tanto o pensamento de Keynes - que se apresenta

\begin{tabular}{|l|l|l|l|l|}
\hline Revista Dialectus & Ano 1 & n. 2 & Janeiro-Junho 2013 & p. 50-59 \\
\hline
\end{tabular}


nas publicações desta linha teórica: Joseph Stiglitz (2003), Robert Shiller (2006), Paul Krugman (2009), entre outros -, quanto o pensamento de Marx através de crescentes publicações de prestigiados intelectuais marxistas, aceitos pela própria academia burguesa, em torno da temática: Más allá de El Capital de Michel Lebowitz (2004), Para Além do Capital de Istvan Mèszáros (2002), The Importance of Marx, 150 Years after the Grundrisse de Eric Hobsbawm (2009), L'Idée du Communisme, de Alain Badiou e Slavoj Zizek (2010), entre outros. Apesar de um marxismo acadêmico, subsumido aos imperativos categóricos do paradigma dominante e, grosso modo, rebaixar o status da teoria de Marx à coadjuvante da ciência oficial, o que dificulta enormemente a teoria de Marx se constituir em alternativa autônoma, aporta elementos teóricos que dificilmente o "marxismo empírico" desenvolveria de per si.

E o que traz de novidade este ressurgimento da literatura marxista na análise da crise do capital? Em termos sintéticos e a propósito de propedêutica, o problema fundamental arguido pelas análises do marxismo ocidental é a revalorização dos Grundrisse (2009; 2011), considerado os rascunhos de O Capital de Marx, de 18571858. Em termos filosóficos neste se recupera a concepção do método, enfatizando as categorias dialéticas da lógica subjetiva tomadas de empréstimo do sistema filosófico hegeliano, embora o próprio Marx (1977), no Prefácio à Contribuição Para Crítica da Economia Política de 1859, tenha censurado a publicação destes rascunhos sem a devida revisão e preparação por ele para uma publicação, como se observa em seus manuscritos ulteriores, de 1861 à 1863, e a genial síntese efetuada em $O$ Capital de 1867. Neste, em seu posfácio à $2^{\mathrm{a}}$ Edição Alemã (1873), Marx indica que "Por sua fundamentação meu método dialético não só difere do hegeliano, mas é também a sua antítese direta" (MARX, 1985, Livro I, Vol. I, p. 20-21). Contudo, a questão mais importante e que estriba todas as teses desta nova literatura marxista sob a hegemonia do "marxismo ocidental", é a questão da superação da lei do valor no capitalismo que Marx desenvolve em uma abstração partindo da tendência à aplicação do capital fixo na produção (composição orgânica do capital) e as relações entre o tempo necessário e tempo excedente (valor abstrato) e o tempo ocupado e o tempo livre da produção na sociedade. Daí, a conclusão lógica de quanto maior a composição orgânica do capital, menor a validade da categoria tempo socialmente necessário como medida de valor na sociedade, passando esta ao tempo livre da produção, dedicada ao gozo e desfrute da mesma, para além das necessidades imediatas e básicas. Portanto, uma mudança radical no paradigma de valor que embasa todas as relações sociais na sociedade capitalista.

\begin{tabular}{|l|l|l|l|l|}
\hline Revista Dialectus & Ano 1 & n. 2 & Janeiro-Junho 2013 & p. 50-59 \\
\hline
\end{tabular}


(MARX, 2009, Vol. II, p. 227-229)

\section{Conclusão}

A emergência de uma filosofia política para a crise do capital fundamenta-se nas evidências de que as crises significam histórica e empiricamente momentos de negação objetiva do paradigma dominante da economia política e da ação estatal da sociedade capitalista atual. Ela também se expressa na crise de paradigma e aduz como evidências o afluxo da literatura especializada que revela além da anomia do paradigma dominante, a limitação gnoseológica do material fático das crises e a incapacidade de se defender da crítica à sua explicação insuficiente da natureza e implicações das mesmas para a sociedade. Na literatura crítica ex post facto é visível tanto o ressurgimento teórico de Keynes através do neokeynesianismo (cf. TOBIN, 1986, p. 238) ${ }^{5}$, quanto de Marx através da "esquerda acadêmica", sinalizando uma inversão histórica do processo dialético em que estes pensamentos teóricos surgiram e se embateram no passado. No processo atual, o keynesianismo ressurgiu como negação imediata e prática do paradigma neoliberal nas ações governamentais; o marxismo, como negação da negação, mais teórica que prática, embora apareça residualmente nas nacionalizações de empresas financeiras e industriais em alguns países, denunciando as limitações tanto do neoliberalismo como do neokeynesianismo.

Esta assertiva apoia-se também nos organismos internacionais que na atualidade têm a mesma função da histórica Conferência de Bretton Woods (instância de consenso normativo dos paradigmas gerais do sistema econômico): a instituição do Nobel, o Fórum de Davos, o Consenso de Washington, e outros. Em termos de paradigma econômico, a premiação do Nobel a Paul Krugman em 2008, significou a mudança do paradigma neoliberal ao keynesiano. Portanto, não é arbitrário supor o ressurgimento de Marx em negação a negação ou superação da macroeconomia como um todo, mesmo que surja uma "nova" síntese entre neoliberalismo e neokeynesianismo, como predica Tobin (1986) e Mankiw (2006). Isto não mudará os efeitos dramáticos da crise sobre a sociedade e a exigência aos sujeitos cognoscentes de nova concepção filosófica da finalidade e rasion d'être da mesma.

A crise do capital, enquanto crise de paradigmas da ciência e, consequentemente,

\footnotetext{
${ }^{5}$ Palestra proferida na Easter Economic Association, Filadélfia, em 10 de Abril de 1986.
}

\begin{tabular}{|l|l|l|l|l|}
\hline Revista Dialectus & Ano 1 & n. 2 & Janeiro-Junho 2013 & p. 50-59 \\
\hline
\end{tabular}


da educação [atividades humanas virtualmente transformadoras e forças produtivas sociais (cf. MARX, 2009, Vol. 2, p. 302-303; 1973, p. 7-8), posto que têm, em tese, o objetivo comum de produzir e reproduzir a consciência científica e técnica formal da sociedade nas novas gerações humanas (cf. MANACORDA, 2007, p. 43-53; passim)], não podem se esquivar à temática: por um lado, porque a educação como atividade desdobrada em ensino e pesquisa, tem por pressuposto as teorias comprovadas e instituídas como paradigmas nas diversas disciplinas da cognição (cf. VYGOTSKY, 1991, p. 22-23) logo, a ciência é condição necessária à sua existência; por outro, a medida em que as crises emergem da acrisia $^{6}$ teórica de uma disciplina científica cujo material fático atravessa todo o campo de objetos que abarcam as ciências sociais - como é o caso da economia -, então sua afecção por tal problemática torna-se tema de primeiro plano, posto que afecciona também de forma mediada e imediadamente todos os elementos substantivos do seu fazer produtivo: docente-ciência-discente (cf. MARX, 1985, Liv I, Vol I, p. 283-284, 1977, p. 27-31, passim).

Porém, a problemática é mais profunda do que se supõe, posto que a contradição intrínseca à dialetização entre produto teórico e atividade cognoscente, diz respeito à universalidade das ciências - subsumida aos paradigmas definidos nos países do capitalismo avançado, em sua maior parte controlada pelos centros de P\&D das grandes corporações monopolistas e oligopolistas globais (cf. MUELLER; OLIVEIRA, 2003, p. 59-65; passim) - e a particularidade da realização da atividade cognitiva - mediatizada pelas instituições e organismos governamentais que, em tese, expressam as prioridades gerais da sociedade historicamente determinada -; e ainda, a própria singularidade do desenvolvimento científico e educacional em que os sujeitos cognoscentes estão inseridos. Tudo isto sugere uma solução de maior envergadura, quiçá comparável ao ato realizado pela Europa quando se libertou do domínio eclesiástico. Assim, a hipótese teórica específica sobre a educação é que uma crise de paradigmas na ciência conduz a primeira necessariamente ao afastamento de seus fins. Portanto, a crise de paradigma na ciência implica a perda de efetividade do ensino porque imobiliza a pedagogia, amplia o hiato entre a teoria e a prática social, com isto, a contradição entre a escola e a vida real, o docente e o discente, embotando o desiderato pedagógico atribuído pela sociedade à Educação. Nestas circunstâncias, vale lembrar Marx: “o homem não é só um animal

\footnotetext{
${ }^{6}$ Segundo Shiller: "There was not the kind of investor euphoria or madness described by some storytellers, who chronicled earlier speculative excesses like the stock market boom of the 1920s" (SHILLER, 2005).
} 
social, em sua expressão mais literal é um animal político" (MARX, 2009, p. 4). A saída da pedagogia é chamar a filosofia em seu concurso.

\section{Referências Bibliográficas}

BEVILAQUA, Aluisio Pampolha. A Crise do Capital em Marx e suas Implicações nos Paradigmas da Educação: Contribuição ao Repensar Pedagógico no Século XXI, Rio de Janeiro: Inverta; Fortaleza, Edições UFC, 2011.

INTERNATIONAL MONETARY FOUND - IMF Washington DC. Word Economic Outlook: Rebalancing Growth. Washington DC: Multimedia Services Division, April 2010.

FRIEDMAN, M. Capitalismo e Liberdade, São Paulo: Nova Cultural, 1982-1985.

GRAMSCI, Antonio. El Materialismo Histórico y la Filosofia de Benedetto Croce, Buenos Aires: Ediciones Nueva Visión. 1971

KEYNES, Jonh M. A Teoria Geral do Emprego, do Juro e da Moeda: Inflação e Deflação, São Paulo: Nova Cultural,1985.

KRUGMAN, Paul. O Regresso da Economia da Depressão e a Crise Actual, $3^{\circ}$ ed. Lisboa: Presença, 2009.

KUHN, Thomas S. La Estructura de las Revoluciones Científicas, México Fondo de Cultura Económica, 1971.

LENINE, V. I. Cadernos Filosóficos, Moscú: Edítorial Progreso, OC, Tomo 29, 1986.

El Imperialismo, Fase Superior del Capitalismo, Moscú: Edítorial Progreso, OC, Tomo 27, 1985 b.

MANACORDA, M. Alighiero. Marx e a Pedagogia Moderna, Capinas, São Paulo: Editora Alínea, 2007.

MANKIW, N. G. El Macroeconomista como Científico y como Ingeniero, Buenos Aires: Desenvolvimiento Económico Revista de Ciencia Sociales, Vol. 47, n.185, AbrilJunio, 2007.

MARX, Karl. O Capital: Crítica da Economia Política, São Paulo: Nova Cultural, 3 Livs. 5 Vols, 1985. Os Economistas.

Elementos Fundamentales para la Crítica de la Economia Política (GRUNDRISSE) 1857-1858, México, DF: Buenos Aires; Madrid: Siglo Veintiuno Editores, 3 Vols., 2009.

Contribuição para a Crítica da Economia Política, $5^{\text {a }}$ Edição, Lisboa:

Editorial Estampa, 1977.

\begin{tabular}{|l|l|l|l|l|}
\hline Revista Dialectus & Ano 1 & n. 2 & Janeiro-Junho 2013 & p. 50-59 \\
\hline
\end{tabular}


O Dieciocho Brumario de Luis Bonaparte, OE, Moscú: Editorial

Progresso, Tomo I, 1973.

MÈSZÁROS, István. Para Além do Capital: Rumo a uma teoria da transição, $2^{\circ}$ Re., São Paulo: Boitempo, 2002/ 2006.

MILL, Stuart. Princípios de Economia Política: Com algumas de suas Aplicações à Filosofia Social. $2^{a}$ ed. São Paulo: Nova Cultural, 2 Vols., 1986.

MUELLER, Suzana P. M.; OLIVEIRA, Hamilton V. Autonomia e Dependência na Produção da Ciência: uma base conceitual para estudar relações na comunicação científica. Belo Horizonte: in Perspect. cienc. inf., v. 8, n. 1, p.58-65, jan./jun. 2003.

SHILLER, Robert J. Irrational Exuberance, New Jersey: Princenton University Press, 2005.

STIGLITZ, Joseph. Information and the Change in the Paradigm in Economics, Prize lecture, December 8, 2001. Columbia Business School, Columbia University, Disponível em: http://nobelprize.org/nobel_prizes/economics/laureates/2001/stiglitz- lecture.pdf, acesso: 20 de Mar 2009.

TOBIN, James. O Futuro da Economia Keynesiana: Palestra proferida na Easter Economic Association, Philadelphia. Abril, 1986. In, Pesquisa e Planejamento Econômico, Rio de Janeiro: Vol. 16, n. 2, pp. 237-250, ago. 1986.

VYGOTSKY, L. S. A Formação Social da Mente: O Desenvolvimento dos Processos Psicológicos Superiores, $4^{\mathrm{a}}$ ed. São Paulo: Martins Fontes, 1991.

VOLTAIRE, François-Marie Arouet. Cândido, Edição Ridendo Castigat Mores, 1759, eBookBrasil.com, Disponível em: www.jahr.org. acesso em: 21/10/2010. 